\title{
Targeting, labelling and stigma: challenging the criminalisation of children and young people
}

By creating 'outsiders' ... labelling invariably gives rise to repeat interventions of increasing intensity that ... ultimately establish, consolidate, and/or confirm offender 'identities'. Such 'identities' attract further intervention and/or negative reaction and so the process continues. (Goldson, 2010)

As the above quote attests, labelling theorists recognise the harmful impact of formal system contact on the individual and contend that problems occur when members of society become intolerant towards the individual's offending, forming a 'negative social reaction', invoking damaging consequences for the 'offender' (ibid).

The forming of 'negative social reactions' combined with the 'application of stigmatising labels' provide the substance for the application of more intensifying forms of intervention, resulting in the forming of the offender label (ibid).

Alternatively, rather than resorting to the formal youth justice apparatus to address criminal behaviour, informal, adequately resourced community based services seem to be much more promising with regard to tackling the occurrence of problems for children and young people and preventing crime. This paper contends that young people are labelled and stigmatised by engaging in early-preventative intervention; continually viewed in a negative light; and are unable to overcome the negative outsider' label attached to them. What is more, the paper contends that girls are drawn into the system for welfare rather than crime related matters and youth justice policy and practice ignores girls' gender-specific needs.

\section{Targeted youth crime prevention and early intervention}

A drastic increase in children and young people entering the system has occurred primarily due to the deployment of wide-ranging crime prevention measures, drawing young people, unnecessarily into the system for engaging in minor criminal activity. This has resulted in 'an avalanche of policy and practice initiatives that aim to target both those vulnerable and those most at risk of future problems ... built up from a deficit model where youth are seen as being bad' (France, 2009). In turn, young people 'at risk' and in need of support are increasingly being dealt with by resort to the formal Youth Justice System. Indeed, the increased demand in youth justice services - and the subsequent increased resort to the formal youth justice apparatus - could be attributed to the 'cut backs' that have severely impacted upon generic youth services for children and young people. Moreover, although the Asset assessment tool (an instrument used by practitioners to determine the likelihood in a young person committing further criminal offences) can be useful in terms of guiding practice towards the identification of problems that need addressing, there are difficulties in assessing/ identifying crime-related problems, with young people often requiring 'welfare' support that seem not to correlate with their offending behaviour. Indeed, the social welfare system has failed to properly support girls with regard to promoting their welfare, and consequently girls experiencing welfare difficulties continue to receive support via entrance to the Youth Justice System. More than this, it is apt to state that the contemporary Youth Justice System, in its rigorous, actuarial pursuance of risk management, fails to distinguish between 'genders' within its formulaic assessment documentation (Creaney, 2012). 


\section{Girls in the Youth Justice System}

Explicit attention has centred upon developing and aspiring towards an 'equitable' youth justice policy and practice agenda, paradoxically resulting, however, in the increased criminalisation of girls' anti-social behaviours. More than this, introducing girls to these new criminalised procedures and resorting to the formal process has been accompanied by a persistent neglect of their gender-specific needs. This has, unsurprisingly, resulted in girls feeling dissatisfied at the lack of availability in gender specific provision. Moreover, the principle aim of preventing offending, the resultant 'up-tariffing' of girls' criminal behaviours, and ensuing early interventionist strategies have been underpinned by a risk-conscious ideology: " "needs talk"... [being] replace[d] [with] "risk talk" and "high need" women becom[ing] "high risk" women...' (Worrall, 2001). This fixation with managing risk is ironic, given that it is unlikely that girls' will actually commit any serious criminal offences, as the risk posed by girls' is 'relatively slight' (ibid).

\section{Labelling, stigma and criminalisation}

Proponents of needs-based universal services premised upon 'voluntary engagement' and 'person-centred' methods of practice, contend that targeted youth justice early preventative measures label and stigmatise young people unfairly 'missing some of those most in need because they do not fall into technically constructed frameworks of assessment' (Williamson, 2009). Importantly 'some groups identified as 'at risk' require and demand disproportionate levels of intervention, and ... only an individualised or personalised response is [deemed] likely to be effective' (ibid). However, although it seems to be somewhat commonsensical that youth justice professionals can 'effectively' predict the young person who is going to engage in criminal activity, practitioners could 'get it wrong', resulting in young people unfairly labelled and stigmatised. Indeed, although primarily designed to help and support young people, benevolently constructed early-preventative youth justice processes have the potential to impact negatively upon young people, resulting in the unintended occurrence of labelling and stigmatisation. Consequently the young people feel less inclined to partake in lawabiding behaviour having been categorised, and embraced the concept of an 'outsider' (Creaney, 2012).

\section{A way forward}

The policy and practice momentum to prevent youth crime via the instigation of various preventative initiatives has resulted in vast numbers of young people drawn into an ever-increasing net of 'correctional intervention'. Principally designed to provide support to children and young people identified to be 'at risk' of crime/antisocial behaviour, benevolently constructed early preventative measures apparently divert potential 'offenders' away from the formal criminal process. However there appears to be a lack of emphasis on the young person's strengths, and an apparent fixation with the young person's deficits: young people are persistently viewed to be 'risky'. These early-preventative measures appear to criminalise and draw young people into the youth justice remit, unnecessarily. Conversely, diversionary principles, predicated upon an avoidance of labelling and stigma, provide that young people should be diverted away from damaging formal interventions. Diversionary 
measures are positive and constructive, offering a more progressive alternative to the formal process. Similarly McAra and McVie (2007) have observed that 'the key to reducing offending lies in minimal intervention and maximum diversion'. Interestingly, in response to the classification of an 'outsider', 'doing less rather than more in individual cases may mitigate the potential for damage that system contact brings ...' (ibid).

\section{Inappropriate criminalisation}

Responding to the occurrence of stigma, labelling and early/inappropriate criminalisation attributed to early preventative measures; informal/diversionary measures appear to be more appropriate in tackling the problematic behaviour of children and young people. Premised upon gender-specific and child centred principles, this alterative model purports to enhance young people's strengths, sufficiently meet young people's welfare-needs, and effectively reduce the occurrence of problematic behaviour (Creaney, 2012). This requires adopting sensitivities towards children and young people, understanding that they are delicate human beings, continually developing, and testing boundaries (ibid). In summary young people require care and attention, rather than control or corrective forms of intervention.

\section{References}

Creaney, S. (2012), 'Risk, prevention and early intervention: youth justice responses to girls', Safer Communities, 11 (2), pp. 111-120.

France, A. (2009), 'Young People' in Fraser, S., Lewis, V., Ding, S., Kellett, M. and Robinson, C. (eds.), Doing Research with Children and Young People, London: Sage.

Goldson, B. (2010), 'The sleep of (criminological) reason: Knowledge- policy rupture and New Labour's youth justice legacy', Criminology and Criminal Justice, 10 (2), pp. $155-178$.

McAra, L. and McVie, S. (2007), 'Youth Justice? The Impact of System Contact on Patterns of Desistance from offending', European Journal of Criminology, 4 (3), pp. 315-45.

Williamson, H. (2009), 'Integrated or targeted youth support services: an essay on prevention', in Blyth, M. and Soloman, E., Prevention and youth crime: Is early intervention working?, Bristol: The Policy Press.

Worrall, A. (2001), 'Girls at Risk? Reflections on Changing Attitudes to Young Women's Offending', Probation Journal, 48 (2), pp. 86-92. 